\title{
Histopathological aspects of co-administration of dexamethasone and diclofenac sodium on male albino rats
}

\begin{tabular}{|c|c|c|}
\hline Abdalmuhaimn Y. Sharef ${ }^{1 *}$ & Bushra Ahmed Hamdi $^{1}$ & Zahra Abdulqader Alnajar ${ }^{1}$ \\
\hline & Abstract & \\
\hline
\end{tabular}

Background and objective: Treatment of an animal with dexamethasone will result in sinuses extension, fat accumulation in the liver, and enlargement of hepatocytes. Whereas, non-steroidal anti-inflammatory drugs (diclofenac sodium) administration may lead to degeneration and formation of wide areas in the form of sinusoidal. Hydropic degeneration possibly is seen in the tubular epithelial cells of the kidney tissue. This study aimed to assess the toxic and side effects of dexamethasone and diclofenac sodium on the liver and kidney in rats, whether used separately or together.

Methods: A total of 40 male albino rats were divided into four groups of ten in each, including the control group. One set was treated with dexamethasone $(1.6 \mathrm{mg} / \mathrm{kg} / \mathrm{day})$, the other was treated with diclofenac sodium $(30 \mathrm{mg} / \mathrm{kg} /$ day $)$, and the last was treated with both drugs together at the same dose without mixture. Both drugs were administered intramuscularly for 30 days. Sections from the liver and kidney were stained by Hematoxeline and Eosin, then examined under a microscope.

Results: Histopathological variation in the liver and kidney tissue of the treated animals have revealed that each drug (dexamethasone, diclofenac sodium) showed a significant alteration. Strong changes $(+++)$ were observed in kidney tissue include degeneration, inflammatory aggregation, fibrosis, and edema, whereas in liver showed central vein dilatation, necrosis, and kupffer cells hyperplasia. Treating with the two drugs together, less alteration $(+)$ in the tissues was noticed.

Conclusion: The effect of both used drugs (dexamethasone and diclofenac sodium) was observed on the liver and kidney tissues of the experimental animals (rats) regardless of being applied separately or the two together. A probable inhibition role of the two drugs on each other have been noticed that lead to call for more detail investigation on this matter in years to come.

Keywords: Dexamethasone; Diclofenac sodium; Liver; Kidney.

\section{Introduction}

There is considerable evidence that dexamethasone as a type of corticosteroid medication has been well documented. It is a potent synthetic glucocorticoid medication for multitudinous inflammatory and immunological disorders. ${ }^{1}$ The liver is the primary metabolic target of dexamethasone action, and acute high doses of it caused hepatic steatosis and showed mild to moderate arteriosclerosis in aorta. ${ }^{2}$ Dexamethasone stimulate the mobilization of free fatty acids from adipose tissue and could also contribute to the development of hepatic lipidosis. ${ }^{3}$ Renal damage is one consequence of early-life, overexposure, impairs nephrogenesis and reduces glomeruli numbers, which may contribute to hypertension in late life. ${ }^{4}$ Another drug Non-steroidal antiinflammatory drugs (NSAIDs) are widely employed in the treatment of musculoskeletal diseases, both for their anti-inflammatory activities as well as their analgesic properties. ${ }^{5}$ NSAIDs inhibit both COX-1 and COX-2 enzymes. The binding

${ }^{1}$ Department of Clinical Analysis, College of Pharmacy, Hawler Medical University, Erbil, Iraq.

* Correspondence: yusif_abdul@yahoo.com 
of NSAIDs to COX isozymes inhibits the synthesis of prostaglandin. ${ }^{6}$ The liver is an organ that is mainly involved in the conversion of drugs into forms that can be easily eliminated out of the body. The mechanism which is responsible for the hepatic toxicity has been found to be the formation of toxic metabolites and covalent binding of the drugs to the hepatic proteins. ${ }^{7}$ On the other side, kidney is an important target site for the effect of diclofenac sodium in humans as well as in animals. ${ }^{8}$ The aim of this prospective study was to find out the histological alterations of the liver and kidney of rats treated with (co-administered diclofenac sodium and dexamethasone) and to compare the alterations between two drugs.

\section{Methods}

\section{Experimental Animals}

Forty male Albino rats, weighing 170-200g, aged averaged 6months were used in this study from the animal house unit of the College of Medicine, Hawler Medical University. Animals were handled and received humane care depending on the ethical principles of the National Institutes of Health's Guide for the Care and Use of Laboratory animals. They were maintained at $\left(22 \pm 3^{\circ} \mathrm{C}\right)$ under a $12 \mathrm{~h}-12 \mathrm{~h}$ light-dark cycle with $50 \%$ to $60 \%$ humidity for at least one week before starting the experiment. The study period extended from April 2018 to November 2018. The animals were divided into four groups, each group containing 10 animals. Group A (control) rats were intramuscularly injected with physiologic saline ( $1 \mathrm{cc}$ per rat), Group B rats were intramuscularly injected with dexamethasone $1.6 \mathrm{mg} / \mathrm{kg}$ per day. Group $C$ rats received a dose of Diclofenac Sodium(30 mg/kg per day) intramuscularly. Group D rats received a daily dose of both dexamethasone (1.6 mg/kg per day) and Diclofenac Sodium (30 mg/kg per day). Twenty four hours after the last injection at the end of 30 days, all the rats were sacrificed. Small specimens from the liver and kidney were collected and rapidly fixed in buffer formalin solution for at least 24 hours.

Histopathological Examination:

Specimens of liver and kidney were processed through the convential paraffin embedding technique (processed through graded alcohols and xylene, and embedded in paraffin blocks). A rotary microtome was used to cut the tissue into 4-5 $\mu \mathrm{m}$ thick sections. All sections were put in a water bath to plain the tissues, then fixed on a glass slide, and then placed for drying on the hot plate. Hematoxylin and eosin staining was employed to study various histopathological changes in the liver and kidney tissue. The slides were examined and photographed under a light microscope.

\section{Statistical analysis:}

Data of histopathological aspects of liver and kidney tissues are presented as follows: $(-)$ showing no alteration and $(+)$ $(++)$ and $(+++)$ indicating few, middle and strong changes respectively. The statistical package for the social sciences (version 24) was used for the analysis of the data. Kruskal-Wallis test was used to show the effects of all groups on each of the parameters, and a Mann-Whitney $U$ test was performed to compare the means of each parameter between two groups. The minimum level of significance was set at $P \leq 0.05$.

\section{Results}

\section{Histopathological Findings of liver}

Light microscope evaluation of livers in the control (group A) rats showed normal morphology of the hepatic parenchyma with hepatocytes radiating from the normal central vein to the periphery of the lobules that contain the portal area, therefore no significant deviation in all parameters of the liver (Table 1 and Figure 1). 
Histopathological aspects of co-administration of .......

Zanco J. Med. Sci., Vol. 24, No. (2), August, 2020

https://doi.org/10.15218/zjms.2020.028

Table 1: Histological alteration in liver tissue among four groups*.

\begin{tabular}{|c|c|c|c|c|c|}
\hline Parameter & $\begin{array}{c}\text { Group A } \\
N=10\end{array}$ & $\begin{array}{c}\text { Group B } \\
N=10\end{array}$ & $\begin{array}{c}\text { Group C } \\
N=10\end{array}$ & $\begin{array}{c}\text { Group D } \\
\mathrm{N}=10\end{array}$ & $P$ value ${ }^{1}$ \\
\hline Congestion and Central vein dilatation & _ & +++ & ++ & + & 0.006 \\
\hline Necrotic cell & _ & +++ & +++ & ++ & $<0.001$ \\
\hline Increased fibrous tissue & _ & ++ & + & _- & 0.058 \\
\hline Hypertrophic nuclei & _ & ++ & ++ & ++ & 0.002 \\
\hline Pyknosiskaryorrhexis and karyolysis & - & +++ & +++ & ++ & $<0.001$ \\
\hline $\begin{array}{l}\text { Portal vessel obliterated with Throm- } \\
\text { bus definition formation }\end{array}$ & - & +++ & + & +++ & 0.001 \\
\hline Inflammatory cell aggregation & _ & ++ & +++ & +++ & $<0.001$ \\
\hline Kupffer cell hyperplasia & _ & +++ & + & _ & $<0.001$ \\
\hline Sinusoidal dilation & _ & + & ++ & ++ & 0.003 \\
\hline
\end{tabular}

${ }^{1}$ The data was analyzed by a Kruskal-Wallis to estimate the effect of all groups on each parameter. *Histological evaluation of the parameters were graded as follows: ( $)$ showing no alterations and $(+),(++)$ and $(+++)$ indicating few, middle and strong alterations, respectively.

$\mathrm{n}$, number of animals.

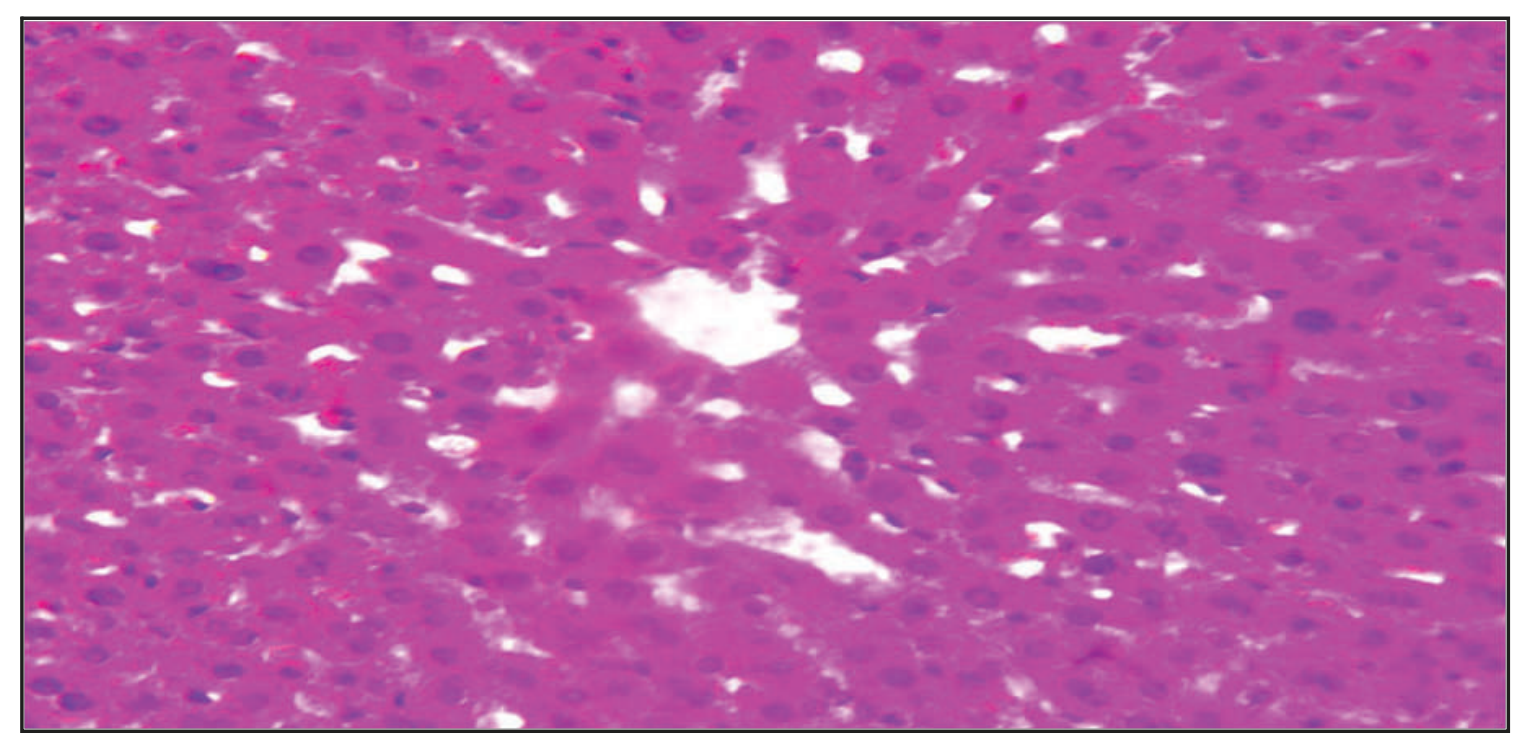

Figure 1: Transfer section of rat liver in control group. No morphological damage was observed in any of the rats, polygonalhepatocytes having sinosoids, normal kupffer cells and hepatic artery .(H\&E.A: X40, BX40). 
Prolongation of dexamethasone treatment for 30 days resulted in the appearance of severe congestion and necrotic cell, indicating tissue damage (Figure 2). Mild fibrous tissue in the liver and inflammatory cell aggregation was observed. The tissue damage was significantly increased as compared with the untreated group (Table 1 and 2).

Table 2: Comparison of each liver parameter between the groups using Mann-Whitney U test.

\begin{tabular}{lcccccc}
\hline Parameter & B\&A & C\&A & D\&A & B \&C & D\&B & D\&C \\
\hline Congestion and Central vein dilatation & 0.001 & 0.019 & 0.056 & 0.206 & 0.057 & 0.521 \\
Necrotic cell & $<0.001$ & $<0.001$ & 0.006 & 0.102 & 0.004 & 0.092 \\
Increased fibrous tissue & 0.015 & 0.148 & 0.342 & 0.184 & 0.061 & 0.547 \\
Hypertrophic nuclei & 0.003 & 0.002 & 0.002 & 0.352 & 0.352 & 1.000 \\
Pyknosiskaryorrhexis and karyolysis & 0.001 & $<0.001$ & 0.001 & 0.873 & 0.230 & 0.092 \\
Portal vessel obliterated with thrombus & $<0.001$ & 0.044 & $<0.001$ & 0.066 & 1.000 & 0.066 \\
Inflammatory cell aggregation & 0.005 & $<0.001$ & $<0.001$ & 0.061 & 0.659 & 0.031 \\
Kupffer cell hyperplasia & $<0.001$ & 0.020 & 0.131 & 0.001 & $<0.001$ & 0.240 \\
Sinusoidal dilatation & 0.007 & 0.001 & 0.002 & 0.332 & 0.776 & 0.460 \\
\hline
\end{tabular}
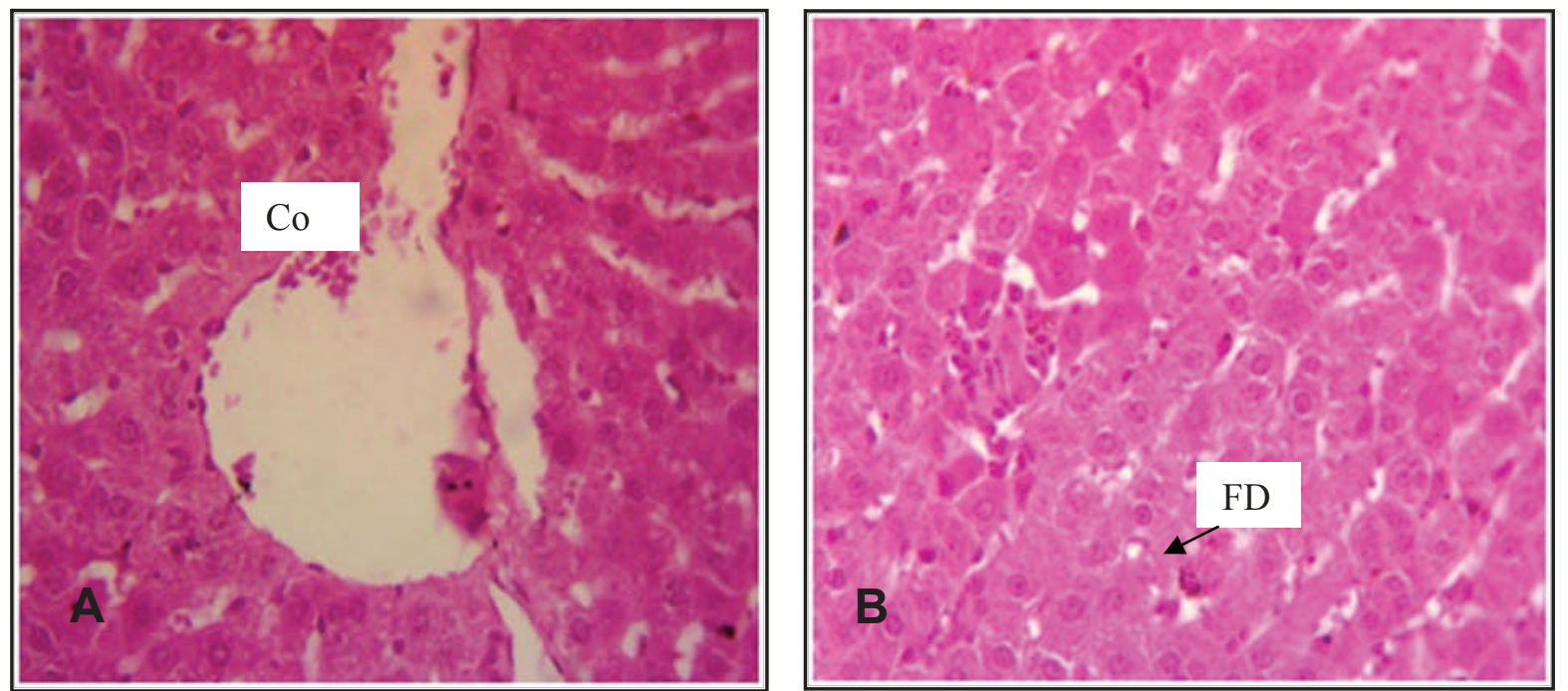

Figure 2: Photomicrograph of rat liver in dexamethasone treated group. A: sever congestion ( $\mathrm{Co}$ )and central vein dilatation. $\mathrm{B}$ : kupffer cell with phagocytic debris (FD). (H\&E.A: X400, BX400). 
Administration of diclofenac sodium for 30 days to adult male rats induced a significant increase in histological changes in liver tissue, sever necrotic cell. Pyknosis, mild dilation of the sinusoid (Figure 3 and Table 1); however, fibrous tissue was not significantly $(P=0.148)$ increased compared with the control group. Our results focused on (group D) rats that were treated with both dexamethasone and diclofenac sodium (Figure 4). Necrotic cells and kupffer cells hyperplasia were significantly decreased. In addition, there was no significant diminution of congestion and dilation of central vein (0.056) as compared with the changes in the dexamethasone treated group. While only inflammatory cell aggregation in group $D$ was significantly decreased $(P=0.031)$, the other pathological changes were not significant compared to diclofenac sodium treated rats (Table 2).
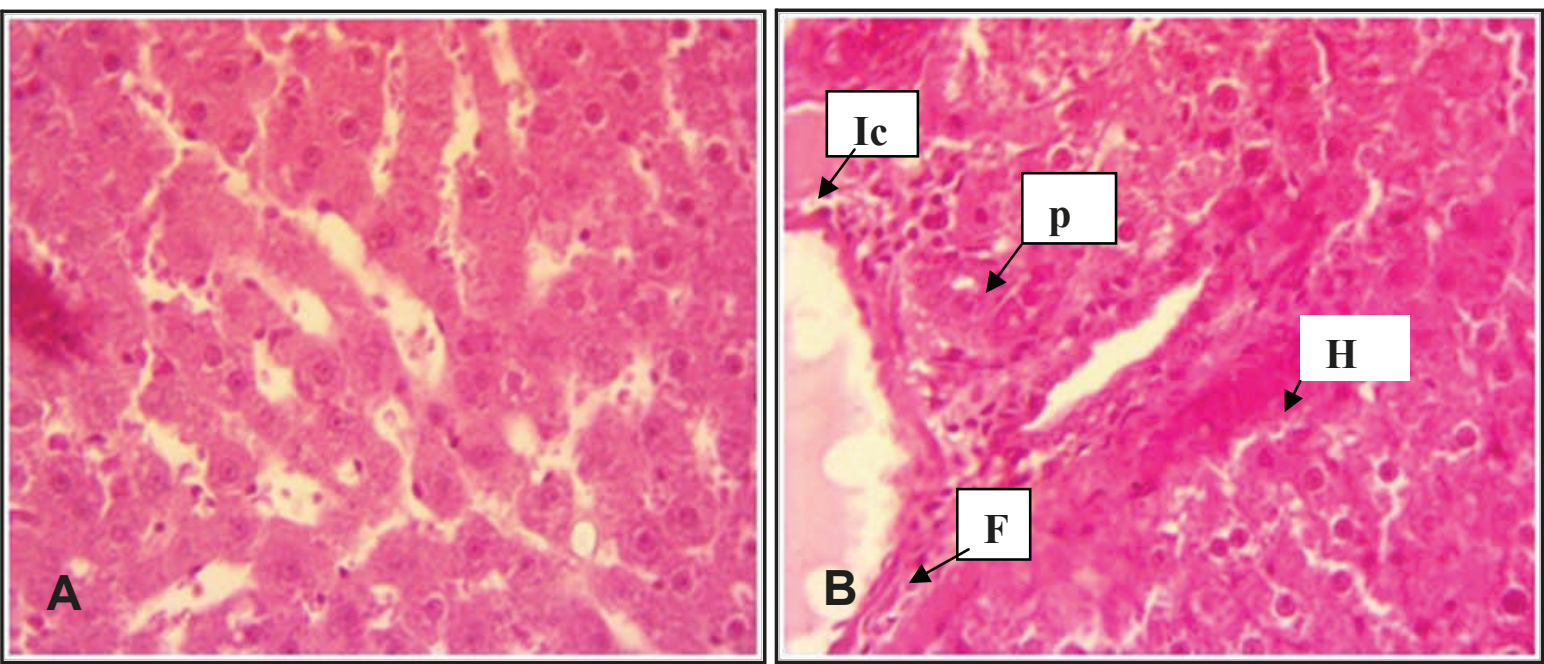

Figure 3: Photomicrograph of rat liver in the diclofenac sodium treated group. A: dilated sinusoid. B: hepatocyte necrosis $(\mathrm{HN})$, fibrosis tissue $(F)$, and inflammatory cell $(\mathrm{IC})$, pyknosis was observed (p). (H\&E.A: X40, BX40).

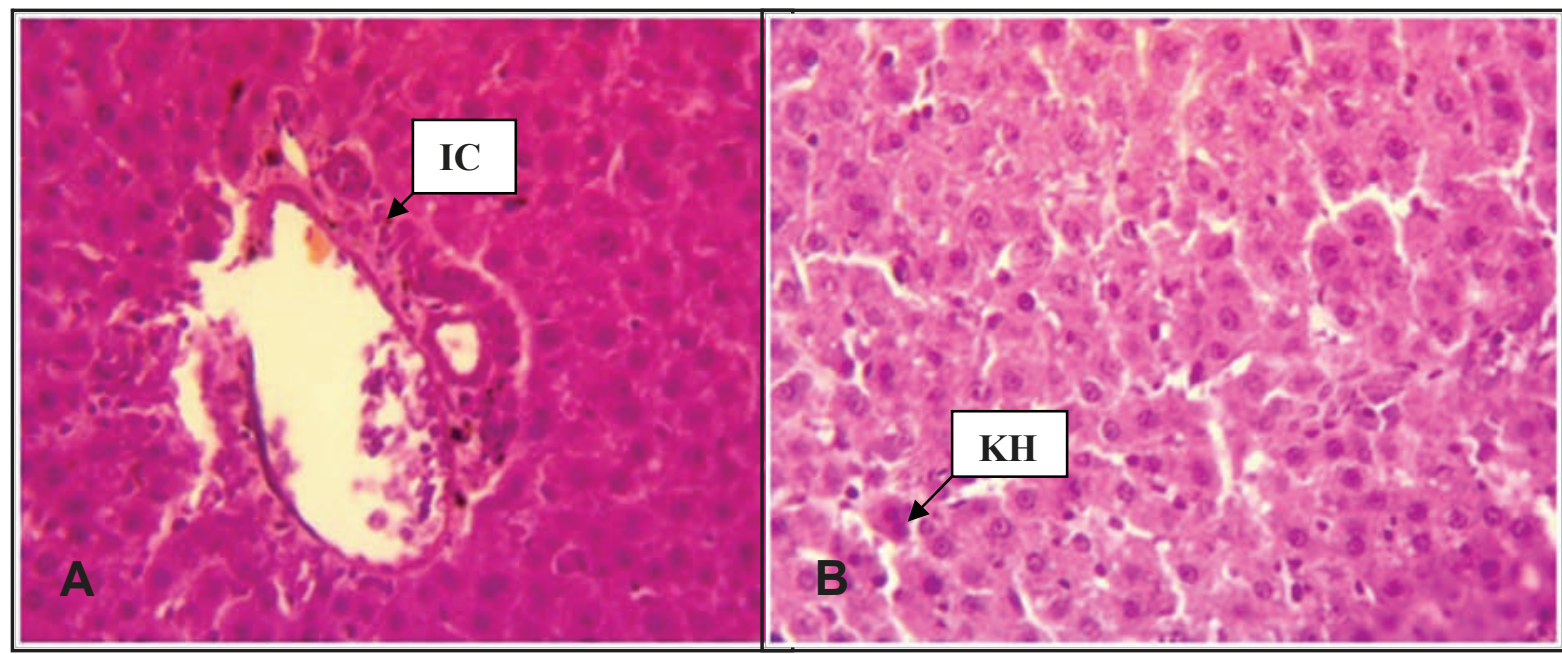

Figure 4: Photomicrograph of rat liver in dexamethasone with diclofenec sodium treated group. A: congestion of portal tract vein with few scattered inflammatory cell (IC). B: kupffer cell hyperplasia( KH). (H\&E.A: X40, BX40). 
Histopathological Findings of kidney

No morphological damage was observed in the kidney tissue of any rats of the control group (A). Normal renal cortical tubules, and normal glomeruli, Sono alteration of all kidneys parameter (Table 3 and Figure 5).

Table 3: Histological alteration in kidney tissue among four groups*.

\begin{tabular}{lccccc}
\hline Parameter & $\begin{array}{c}\text { Group A } \\
\text { N=10 }\end{array}$ & $\begin{array}{c}\text { Group B } \\
\mathbf{N = 1 0}\end{array}$ & $\begin{array}{c}\text { Group C } \\
\text { N=10 }\end{array}$ & $\begin{array}{c}\text { Group D } \\
\text { N=10 }\end{array}$ & $P$ value \\
\hline Vacuolated tubule & - & ++ & ++ & + & 0.001 \\
Cell damage from kidney fibrosis & - & ++ & + & ++ & 0.002 \\
Reversible cell injury & - & ++ & +++ & + & $<0.001$ \\
Inflammatory aggregation & - & +++ & +++ & + & $<0.001$ \\
Atrophic and hyaline deposition of & - & ++ & +++ & + & $<0.001$ \\
glomerular & - & ++ & ++ & + & $<0.001$ \\
Interstitial mononuclear cell infiltration & - & +++ & ++ & ++ & $<0.001$ \\
Detachment of epithelial cell from the & - & & & & $<0.001$ \\
basement membrane & - & +++ & +++ & + & $<0.001$ \\
Odema & - & + & +++ & + & + \\
Vasodilation and congestion & - & + & ++ & + & 0.003 \\
Tubular necrosis & & + & & & + \\
\hline
\end{tabular}

${ }^{1}$ The data was analyzed by a Kruskal-Wallis to estimate the effect of all groups on each parameter. *Histological evaluation of the parameters were graded as follows: ( - ) showing no alterations and $(+),(++)$ and $(+++)$ indicating few, middle and strong alterations, respectively.

$\mathrm{n}$, number of animals.

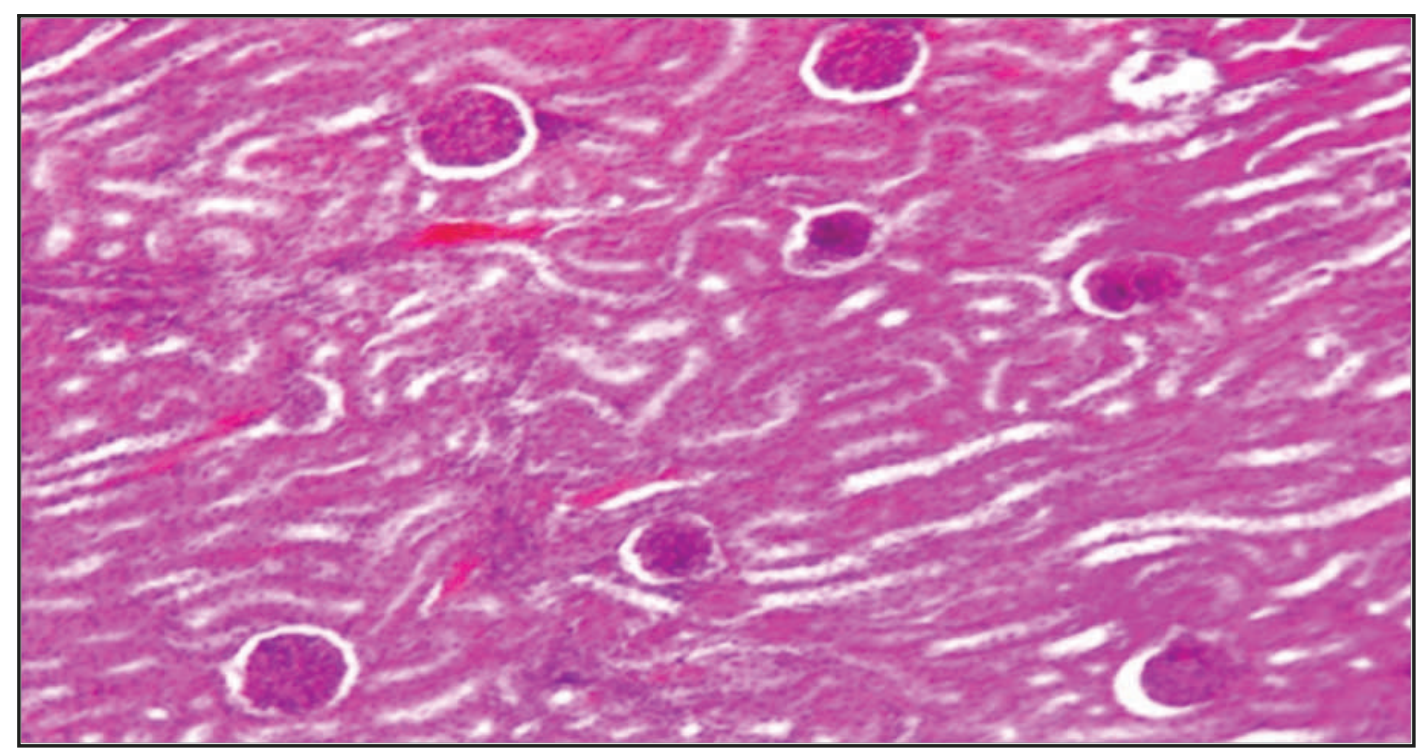

Figure 5: Transfer section of rat kidney in the control group. Normal histological architecture with normal proximal convoluted tubules lined by Cuboidal epithelium. (H\&E.A: X40, BX40). 
In dexamethasone group kidney tissue samples (Figure 6) showed a significant increase of fibrosis, hyaline deposition of glomerular, edema in the proximal convoluted tubule, and necrosis of tubule, however, the later change was not significantly $(P=0.250)$ different as compared with the control group (Table 3 and 4$)$. All the above changes, as well as other alterations mentioned in Table 3 occurred in the diclofenac sodium treated group (Figure 7).

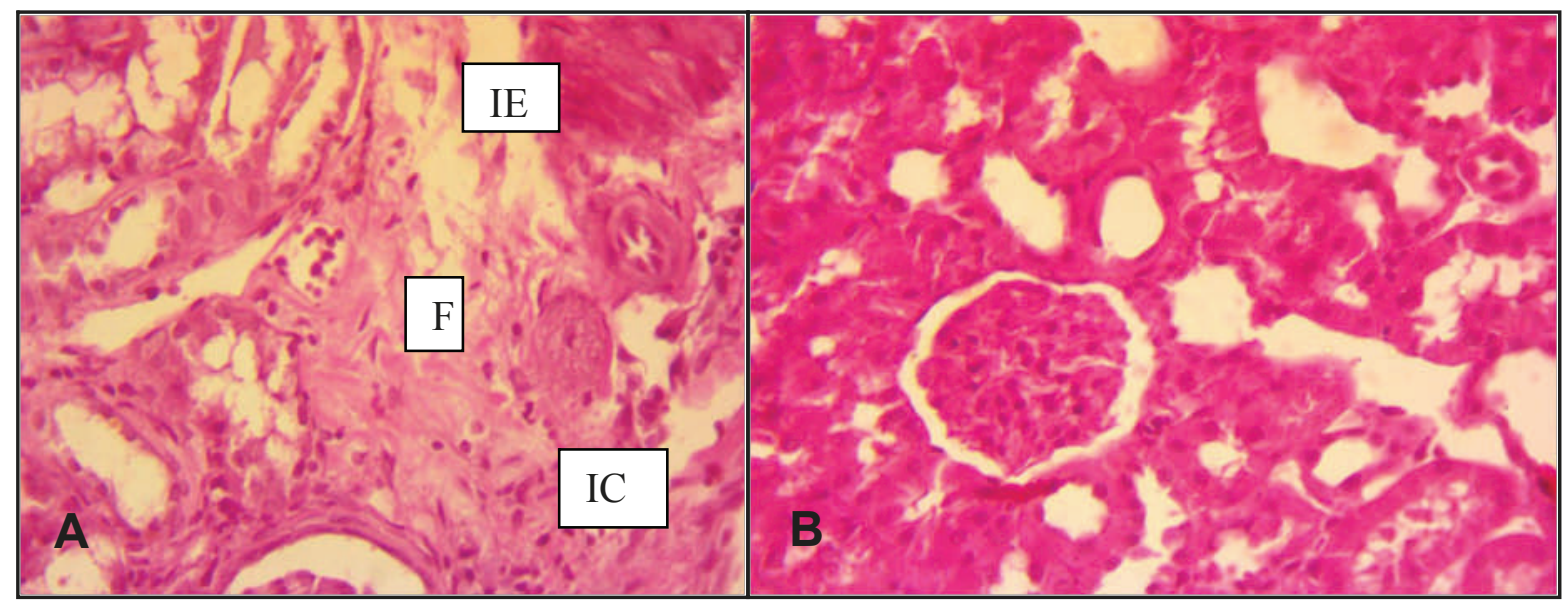

Figure 6: Photomicrograph of rat kidny in dexamethasone treated group. A: moderate fibrosis( $F$ ), inflammatory cell with signs of interstitial edema ( IE). B: glomerulus hyaline thick. (H\&E.A: X40, BX40).

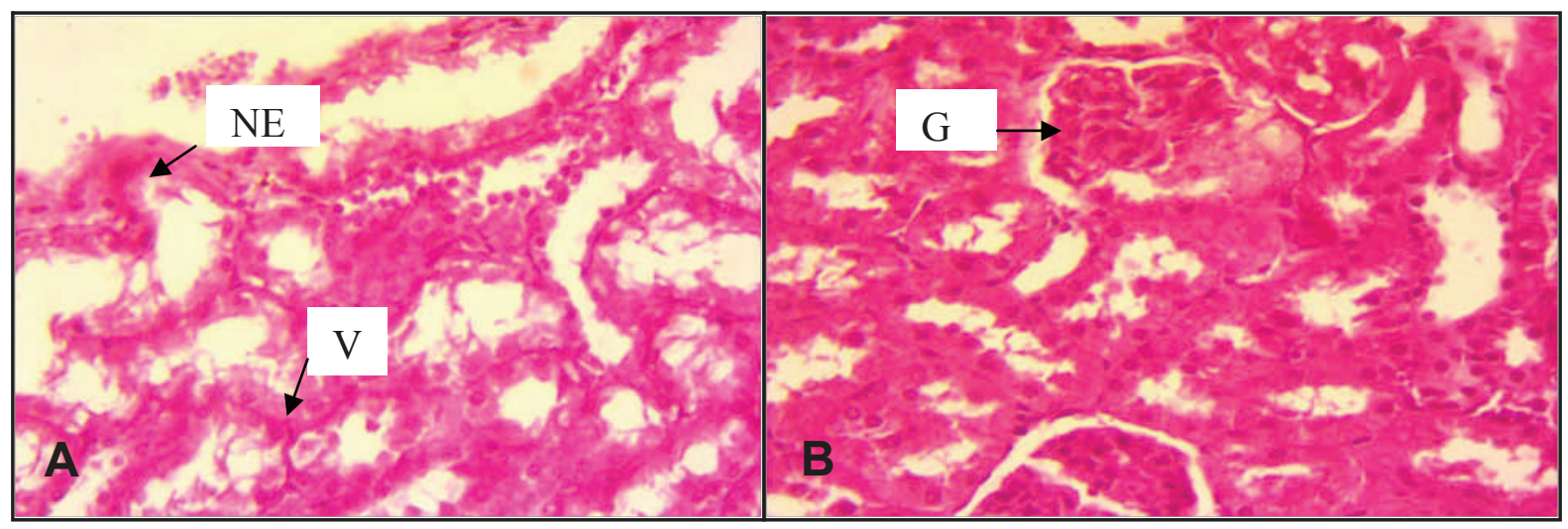

Figure 7: Photomicrograph of rat kidney in diclofenac sodium treated group. A: vacuolated cytoplasm $(\mathrm{V})$, proximal convoluted tubule have a necrotic epithelium (NE). B: glomerulus atrophy (GA) with hyaline focal deposition. (H\&E.A: X40, BX40). 
The most important comparison in our results was between group ( $D$ with $B$ ) and (D with $C$ ). Kidney tissue of rat treated with both dexamethasone and diclofenac sodium showed few vasodilation with congestion, few vacuolated, and necrotic tubules (Figure 8). Only inflammatory aggregation $(P=0.017)$ was decreased significantly when compared with group B. While there was a significant decrease $(P<0.05)$ in atrophic glomerular, interstitial mononuclear cell infiltration, vasodilation and tubular necrosis in group $D$ as compared with group C (Table 4).

Table 4: Comparison of each kidney parameter between the groups using Mann-Whitney U test.

\begin{tabular}{lcccccc}
\hline Parameter & B\&A & C\&A & D\&A & B \&C & D\&B & D \&C \\
\hline Vacuolated tubule & 0.001 & 0.02 & 0.007 & 0.569 & 0.168 & 0.126 \\
Cell damage from kiddey fibrosis & $<0.001$ & 0.018 & 0.002 & 0.114 & 0.202 & 0.574 \\
Reversible cell injury & $<0.001$ & 0.001 & 0.007 & 0.291 & 0.246 & 0.104 \\
$\begin{array}{l}\text { Inflammatory aggregation } \\
\text { Atrophic and hyaline deposition of }\end{array}$ & $<0.001$ & 0.001 & 0.002 & 0.385 & 0.017 & 0.163 \\
glomerular & & $<0.001$ & 0.005 & 0.006 & 0.102 & 0.001 \\
$\begin{array}{l}\text { Interstitial mononuclear cell } \\
\text { infiltration }\end{array}$ & 0.001 & $<0.001$ & 0.20 & 0.078 & 0.314 & 0.025 \\
$\begin{array}{l}\text { Detachment of epithelial cell from } \\
\text { basement membrane }\end{array}$ & $<0.001$ & $<0.001$ & 0.002 & 0.138 & 0.132 & 0.933 \\
Odema & $<0.001$ & $<0.001$ & 0.002 & 0.925 & 0.056 & 0.098 \\
Vasodilation and congestion & 0.007 & $<0.001$ & 0.002 & 0.035 & 1.000 & 0.017 \\
Tubular necrosis & 0.250 & $<0.001$ & 0.066 & 0.067 & 0.702 & 0.039 \\
\hline
\end{tabular}

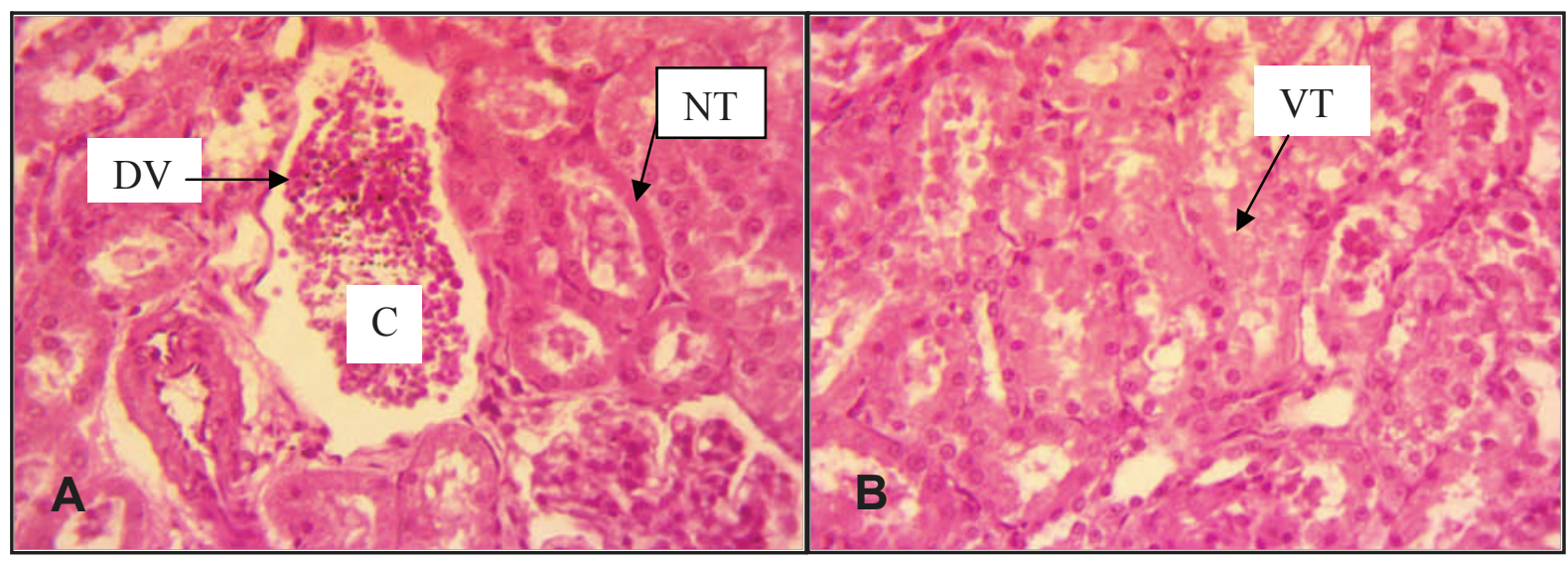

Figure 8: Photomicrograph of rat kidney in dexamethasone with diclofenec sodium treated group. A: dilated vessels (DV) with congestion(C), necrosis of tubule (NT) . B: Vaculated tubules (VT). (H\&E.A: X40, BX40). 


\section{Discussion}

The present research has been conducted to study the effect of combination dexamethasone with diclofenac sodium on hepatic and renal tissue. It has been demonstrated in the previous studies ${ }^{9,10}$ that administration of dexamethasone was induced in increasing the liver fibrosis, necrosis, and slight fatty liver cells, which is in accordance with present results. The possible mechanism is may be due to the dexamethasone causes alteration in lipid metabolism ${ }^{2}$ or production of oxidative stress. It has been stated as a major cause of dexamethasone-induced liver injury and the extrema production of free radicals. ${ }^{11}$ This study revealed that dexamethasone treated rats showed an induce many histological changes, including inflammatory cells infiltration, sinusoidal congestion, and disruption. Our findings are consistent with another study. ${ }^{3}$ These changes may be due to the dexamethasone induced apoptosis and reduced proliferation in a variety of different cells. ${ }^{12}$ Additionally, Melgrt et al. ${ }^{13}$ mentioned different mechanisms explaining the toxicity of dexamethasone on liver tissue. The histopathological changes of the kidney, the dexamethasone administration in rats results in fibrosis, atrophy of glomeruli, and necrosis in the epithelial lining of the convoluted tubules. These changes might be due to the expression of kidney MCP-1 gene, which is increased after treatment of dexamethasone. ${ }^{14}$ This study revealed that co-administration of both dexamethasone and diclofenac sodium enhances the adverse effect on the tissue of each other. The use of dexamethasone may synergize the anti-inflammatory effect of diclofenac sodium and contribute to the reduction of inflammatory exudates. ${ }^{15}$ The hepatotoxic and nephrotoxic effect of non-steroidal anti-inflammatory drugs on experimental animal has been dealt with by many authors. ${ }^{16,17}$ Nevertheless, the precise and exact mechanism of such drugs and their effect results are known to be metabolized in liver tissue. Therefore, the toxic effects of diclofenac sodium might be found in liver tissue and cells. The present results showed that the hepatic necrosis, as well as cell congested central vein with widened blood sinusoid and fibrous tissue proliferation, reflects a quite positive correlation between the diclofenac sodium and the liver damage. Our results agree with those of Mohan and Sharma ${ }^{7}$. Three metabolites of diclofenac sodiumare reported to be responsible for diclofenac sodiumtoxicity in the liver, namely 4Õ hydroxy 3 diclofenac, 5 Õhydroxy 4 diclofenac, and 50 Õ hydroxy 6 diclofenac. ${ }^{18}$ Moreover, the appearanceof periportal hepatocytes as vacuolated cells with pyknotic nuclei may be due to excessive lipid peroxidation. ${ }^{7}$ Our results are compatible with those of authors ${ }^{16,18}$ who reported that diclofenac sodium induced nephrotoxic effects in experimental animals. The main cause of cell damage in kidney tissue is the number of reactive oxygen species can be increased through drug administration, which induced prooxidative damage in renal tissue. ${ }^{17}$ In addition, there were other mechanisms of this drug had mentioned by previous studies. ${ }^{19,20}$ Overall mechanisms of diclofenac sodium might be fluctuated by interfere of dexamethasone result in decline hepatic and renal toxicity as we observed in group $D$ treated rats that most of histopathological changes had improved (Table 1 and 2). However, these changes were not significant when compared with the group treated only diclofenac sodium (Table 3 and 4 ). Most of the previous studies showed that the effect of steroid and non-steroid drugs on various organs. In contrast, in the present study the effect was dealt with a single dose as well as combine doses of both drugs of dexamethasone and diclofenac sodium. The application of drug in this model had shown their effect on both organs more advantageous. This might be the action of one drug inhibit the mechanism of other leading to reduce the toxicity effect on 
hepatic and renal tissue. At last, this investigation may lead to new and more studies in this respect. Taking into consideration other organs and other doses on different animals that ultimately will be a guideline for the background knowledge of the effect of such drugs on different organs on the human being as well.

\section{Conclusion}

The combination of dexamethasone and diclofenac sodium can be used safely; however, their combined effect on (liver and kidney) showed an inhibitory role that may lead to call for more detailed investigations on this matter in the future.

\section{Competing interests}

The authors declare no competing interests.

\section{References}

1. Hapgood JP, Avenant C, Moliki JM. Glucocorticoid -independent modulation of GR activity: Implications for immunotherapy. Pharmacol Ther 2016; 165:93-113.

2. Kumar VH, NagendraNayak IM, Huilgol SV, Yendigeri SM, Narendar K, Rajasekhar $\mathrm{CH}$. Dose dependent hepatic and endothelial changes in rats treated with dexamethasone. J Clin Diagn Res 2015; 9(5):8.

3. Hussein AJ, Majeed MF, Abbas AS. Histopathological Study of Some Organs After Long-Term Treatment With Dexamethasone in Male Rabbits. Science 2014; 30:39.

4. Figueroa JP, Rose JC, Massmann GA, Zhang J, Acuña $\mathrm{G}$. Alterations in fetal kidney development and elevations in arterial blood pressure in young adult sheep after clinical doses of antenatal glucocorticoids. Pediatr Res 2005; 58(3):510.

5. Crofford LJ. Use of NSAIDs in treating patients with arthritis. Arthritis Res Ther 2013; 15(3):2.

6. Altman R, Bosch B, Brune K, Patrignani P, Young C. Advances in NSAID development: evolution of diclofenac products using pharmaceutical technology. Drugs 2015; 75(8):859-77.

7. Mohan D, Sharma S. Histopathological Alterations in Liver of Mice Exposed to Different Doses of Diclofenac Sodium. IntJ Biol 2017; 11(11):73842.

8. Oaks JL, Gilbert M, Virani MZ, Watson RT, Meteyer CU, Rideout BA, et al. Diclofenac residues as the cause of vulture population decline in Pakistan. Nature 2004; 427(6975):630.

9. Eken $\mathrm{H}$, Ozturk $\mathrm{H}$, Ozturk $\mathrm{H}$, Buyukbayram $\mathrm{H}$. Dose-related effects of dexamethasone on liver damage due to bile duct ligation in rats. World $\mathrm{J}$ Gastroenterol 2006; 12(33):5379.

10. Amar MI, Shama IY, Enaia AA, Hind AE, Hager AM. Effects of various levels of oral doses dexamethasone (Al-nagma) abused as cosmetic by Sudanese women on Wistar rats. J Med Sci 2013; 20(13):432-8.

11. Hasona N, Alrashidi A, Aldugieman T, Alshdokhi A, Ahmed M. Vitisvinifera extract ameliorate hepatic and renal dysfunction induced by dexamethasone in albino rats. Toxics 2017; 5(2): 11.

12. Ranta F, Avram D, Berchtold S, Düfer M, Drews $G$, Lang $F$, et al. dexamethasone induces cell death in insulin-secreting cells, an effect reversed by exendin-4. Diabetes 2006; 55(5):1380-90.

13. Melgert BN, Olinga P, Van Der Laan JM, Weert $\mathrm{B}$, Cho J, et al. Targeting dexamethasone to Kupffer cells: effects on liver inflammation and fibrosis in rats. Hepatology 2001; 34(4):719-28.

14. Liu $Y$, van Goor $H$, Havinga $R$, Baller JF, Bloks VW, van der Leij FR, et al. Neonatal dexamethasone administration causes progressive renal damage due to induction of an early inflammatory response. Am J Physiol Renal Physiol 2008; 294:768-76.

15. Abd A,Higzi A.Effects of co-administration of dexametahsone and diclofenac sodium on the post -operative outcomes following mandibular third molar surgery under local anaesthsia. Eipmr 2016; 3(12):11-20.

16. Aydin G, Gökçimen A, Öncü M, Çicek E, Karahan N, Gökalp O. Histopathologic changes in liver and renal tissues induced by different doses of diclofenac sodium in rats. Turk $\mathrm{J}$ Vet Anim Sci 2003; 27(5):1131-40.

17. Gokcimen A, Akdogan G, Karaoz E. Structural and biochemical changes in liver and renal tissues induced by an acute high dose of diclofenac sodium in rats. Biomed Res 2000; 11(3):293-302.

18. El-Maddawy ZK, El-Ashmawy IM. Hepato-renal and hematological effects of diclofenac sodium in rats. Global J Pharmacol 2013; 7(2):123-32.

19. Hickey EJ, Raje RR, Reid VE, Gross SM, Ray $\mathrm{SD}$. Diclofenac induced in vivo nephrotoxicity may involve oxidative stress-mediated massive genomic DNA fragmentation and apoptotic cell death. Free Radic Biol Med 2001; 31(2):139-52.

20. Yasmeen T, Qureshi GS, Perveen S. Adverse effects of diclofenac sodium on renal parenchyma of adult albino rats. J Pak Med 2007; 57:7. 